\title{
Are litter, plastic and microplastic quantities increasing in the ocean?
}

\author{
Francois Galgani ${ }^{1 *}$ (D) Aleke Stoefen-o Brien², Judith Weis ${ }^{3}$, Christos loakeimidis ${ }^{4}$, Qamar Schuyler ${ }^{5}$, \\ Iryna Makarenko ${ }^{6}$, Huw Griffiths ${ }^{7}$, Joan Bondareff ${ }^{8}$, Dick Vethaak ${ }^{9}$, Alan Deidun ${ }^{10}$, Paula Sobral ${ }^{11}$, \\ Konstantinos Topouzelis ${ }^{12}$, Penny Vlahos ${ }^{13}$, Fernanda Lana ${ }^{14}$, Martin Hassellov ${ }^{15}$, Olivia Gerigny ${ }^{16}$, Bera Arsonina ${ }^{17}$, \\ Archis Ambulkar ${ }^{18}$, Maurizio Azzaro ${ }^{19}$ and Maria João Bebianno ${ }^{20}$
}

\begin{abstract}
Whilst both plastic production and inputs at sea have increased since the 1950s, several modelling studies predict a further increase in the coming years in these respective quantities. We compiled scientific literature on trends in marine litter, consisting largely of plastic and microplastics in the ocean, understanding that monitoring programs or assessments for these aspects are varied, frequently focusing on limited components of the marine environment in different locations, and covering a wide spectrum of marine litter types, with limited standardization. Here we discuss how trends in the amounts of litter in the marine environment can be compared with the information provided by models. Increasing amounts of plastic are found in some regions, especially in remote areas, but many repeated surveys and monitoring efforts have failed to demonstrate any consistent real temporal trend. An observed steady state situation of plastic quantities in many marine compartments and the fate and transport of plastic in the marine environment remain areas for much needed further research.
\end{abstract}

Keywords: Plastic pollution, Marine litter, Microplastics, Trends, Monitoring

\section{Introduction}

Plastic cycling in the marine environment and trends in marine litter quantities over time remain important unanswered questions. While it is well established that vast quantities of plastic (a subset of marine litter) enter the ocean annually [19], it remains difficult to assess actual trends in the flux of plastics to the ocean simply because the seafloor is a major sink for marine litter, plastic and microplastics $[3,20,36,47]$. Currently, there are no reliable estimates for either the quantity of plastics sinking to the seafloor, or for the potentially significant input of microplastics via atmospheric deposition [28]. Moreover, the sources of plastic in the marine environment are too numerous to account for and research on their impacts on the marine environment is ongoing.

\footnotetext{
* Correspondence: francois.galgani@ifremer.fr

${ }^{1}$ IFREMER, LER/PAC, Corsica, France

Full list of author information is available at the end of the article
}

It is now a common assumption that there is an excessive amount of plastic in the ocean. This fact, sometimes exaggerated, has been used by stakeholders and NonGovernmental Organizations (NGOs) to advocate for policies and economic solutions to reduce plastic [32]. Though there is a great need for systemic changes in plastic production, use and recycling strategies so as to reduce the volume of plastic in the ocean, it is still unknown whether the quantities of litter, plastic and microplastic abundances are currently actually increasing in the ocean.

While both plastic production and inputs to the sea have increased worldwide [5, 14, 19], plateauing levels of plastics measured at sea could be explained through the fragmentation of larger pieces not previously accounted for, or through their transfer from local to remote areas where measurements are scarce, especially in the deep sea. The question on how physical, chemical or biological degradation may limit the increase of plastics at

\section{Springer Open}

๑ The Author(s). 2021 Open Access This article is licensed under a Creative Commons Attribution 4.0 International License which permits use, sharing, adaptation, distribution and reproduction in any medium or format, as long as you give appropriate credit to the original author(s) and the source, provide a link to the Creative Commons licence, and indicate if changes were made. The images or other third party material in this article are included in the article's Creative Commons licence, unless indicated otherwise in a credit line to the material. If material is not included in the article's Creative Commons licence and your intended use is not permitted by statutory regulation or exceeds the permitted use, you will need to obtain permission directly from the copyright holder. To view a copy of this licence, visit http://creativecommons.org/licenses/by/4.0/. 
sea is not yet resolved. Several modelling studies, based on waste production or extrapolated riverine inputs, predict increasing inputs of plastic to the ocean [11, 14, 17, $19,21,26,27]$, that could be at least partially offset in the future by societal reduction measures $[5,23]$.

\section{Discussion}

A closed mass balance of all marine litter in all seas would be needed to reliably converge on temporal trends. However, such an evaluation is not possible at this stage since fluxes of litter between various components of the marine system, especially rates of sinking and mechanisms of degradation and persistence, are not fully understood. Existing data, however, may help identify the important questions to address. We compiled scientific literature on global trends in marine litter amounts through an extensive search in science databases (See Supplementary material S1 on methods and S2 for a summary of references used). These monitoring programs or assessments most often report on the results of single surveys, discrete water samples, sediments or biota, and cover a wide spectrum of sizes, types, shapes, polymer types and colors, with limited data on nanoplastics. These differences in research techniques and methodologies can mask or amplify trends in marine plastic abundance. For instance, sampling for microplastics with nets often misses fibers and smaller-sized microplastics [34, 40], while studies isolating smaller fractions from water give counts of these materials that are not broadly consistent. Minimum cutoff sizes of microplastics measured in water or sediments differ between studies and are therefore difficult to compare. Plastics recorded in water and sediments are typically significantly larger than microplastics recorded in marine biota. These smaller microplastics that go undetected may cause impacts in marine organisms [15] and potentially lead to in human health effects [2]. Counting particles under a microscope has limitations. Smaller sizes can be missed and it is easy to confuse natural and polymer microfibers. In contrast, techniques such as Raman and FTIR spectroscopy coupled to microscopy can identify smaller-sized microplastics and characterize the nature of the polymers. If, over time, methodologies shift to standardized methods that may include using grab samples or smaller mesh nets or standardized size fractions, increasing attention to clean methods to reduce contamination from air, and harmonised analytical approaches, there will be greater comparability across studies to ascertain trends. Studies from different locations or time periods cannot currently be accurately compared.

When comparing modelling results with empirical data, a temporal increase in marine litter amounts was demonstrated in a limited number of studies for remote parts of the ocean, such as remote islands, the Antarctic [3], the Indian Ocean [10] and the South Atlantic [37], for plastic ingested by south Atlantic petrels [35], and in specific oceanographic features, including converging currents above the Arctic circle [41]. Interestingly, since the 1950s baseline, floating microplastics at sea increased exponentially each decade until the 2000s [42]. Very recently, Wilcox et al. [45] revisited the data on floating microplastics in the North Atlantic Ocean (which did not exhibit any trend from 1986 to 2008, [24]), and Brandon et al. [6] analyzed microplastics in sediments from California collected over a span of 175 years. Both studies suggested an increase in the amounts of microplastics, proportional to plastic production worldwide, as for a local study with very limited samples in the bay of Sydney [46]. However, most of the work based on regular and periodic monitoring surveys has not demonstrated any real trend in these quantities.

For large debris on beaches, an absence of temporal trend was demonstrated for macroplastics in the North Atlantic, between 2001 and 2011 [38], in Chile, between 2006 and 2016 [16] and for data from cleanups in Taiwan, between 2004 and 2016 [44]. An absence of temporal trends was also observed for large floating debris in the Balearic Islands between 2005 and 2015 [7] and in China, between 2007 and 2014 [49]. In addition, collections of marine litter by Continuous Plankton Recorders [33] showed relatively unchanged amounts trapped annually in the North East Atlantic since 2000, following a steady increase since the 1950s.

In seafloor litter studies, no change in plastic pollution was measured in Spain between 2007 and 2017 [12] nor in the North Sea [30]. A slight increase in seafloor plastics was observed in recent years in the Baltic (excluding fishing gear) [48], while results from observations in France, between 1995 and 2017 (23 years), showed mixed trends, of decreasing amounts between 2000 and 2013 and of increases since 2013 [13]. No trend was identified in Chinese waters for sea floor litter between 2007 and 2014 [49], with a large variability in plastics concentration and from data collected during regular State monitoring between 2011 and 2018 [31]. In contrast, a decrease in total seafloor litter was measured between 2007 and 2017, in both the Alboran Sea [12] and the northern Adriatic, [39], without significant temporal trends for plastic in the remaining Adriatic.

For microplastics, floating particles were found at similar levels between 2005 and 2014 in East Greenland [1], in the North Atlantic Subtropical Gyre between 1986 and 2008 [24] and in the North Pacific Subtropical Gyre between 2001 and 2012 [25]. In addition, no changes in floating microplastics $(>150 \mu \mathrm{m})$ were detected between 1987 and 2015 in the Baltic Sea [4], between 1987 and 2012 in the North Atlantic 
subtropical gyre [43] and between 2001 and 2012 in the North Pacific Subtropical gyre [25]. For ingested large debris, constant levels were also demonstrated for stranded cetaceans recorded from Irish waters between 1990 and 2015 [29], and in western Mediterranean sea turtles between 1995 and 2016 [9].

Finally, understanding that quantifications of small ingested microplastics, by mass, may range from 1 to $2 \%$ to $30-90 \%$ of control tests that are positive $[18,22]$, constant levels were also demonstrated for ingested microplastics by little auks in the Arctic [1], in herring and sprats from the Baltic sea between 1987 and 2015 [4], in deep sea benthic invertebrates between 1976 and 2015 [8], and in fulmar (Fulmarus glacialis) from the North Sea [43].

\section{Conclusion and future perspectives}

Most studies indicate constant amounts of litter in coastal marine systems in recent years until 2019. The increase in plastic quantities observed in remote areas over time could therefore be interpreted as a long-term transfer of litter from directly affected areas to regions where human activity is either extremely reduced or non-existent. Nevertheless, while the predicted total global amount of plastic litter is increasing, as suggested by models, the apparent steady state situation of plastic quantities observed in coastal systems challenges our ability to predict plastic sources and fate. More standardization and coordination is needed before we can reliably report on trends in plastic waste. Decreasing marine temporal trends is possible for specific types of plastics, subject to societal reduction measures, as is the case for industrial pellets, which have received much consideration in regional action plans following changes in industrial practices. Formulating scenarios on the future effect of proposed management measures [5,23] is reminiscent of debates starting many years ago around climate change, with model predictions identifying the need for data, leading to longer-term observational efforts. Until the mechanisms behind the apparent steady-state amounts of plastics recorded in surveys across the marine environment are better understood, the identification of possible trends will remain a challenge. There remain many data gaps and uncertainties on the rates of degradation, burial and transport of plastics in the marine domain. Only more scientific research can provide quantification of the plastic pollution problem in marine systems to begin to fully address its sources, thus identifying solutions which must come from the international community through a global ocean governance framework. The basic questions about where marine litter is, goes, how it degrades and cycles in the ocean have definitely not been fully answered and in the upcoming UN Decade for Ocean Sciences, this should definitely be a priority.

\section{Supplementary Information}

The online version contains supplementary material available at https://doi. org/10.1186/s43591-020-00002-8.

\section{Additional file 1}

Acknowledgements

This document was inspired during the preparation of the chapter Marine Litter from the second United Nations World Ocean Assessment (WOA 2) to be published in the coming months and most contributors of the present document were involved in its preparation.

\section{Authors' contributions}

The initial version was drafted by FG, then discussed, corrected and finalized by all authors. The author(s) read and approved the final manuscript.

\section{Funding}

All contributors were self funded.

Availability of data and materials

The present paper is based on published data.

Competing interests

There is no competing interest.

\section{Author details}

${ }^{1}$ IFREMER, LER/PAC, Corsica, France. ${ }^{2}$ World Maritime University, Malmö, Sweden. ${ }^{3}$ Rutgers University, Newark, USA. ${ }^{4}$ UNEP/ Mediterranean Action Plan, Athens, Greece. ${ }^{5} \mathrm{CSIRO}$, Hobart, Australia. ${ }^{6}$ Black Sea commission, Istanbul, Turkey. ${ }^{7}$ British Antarctic Survey, Cambridge, UK. ${ }^{8}$ BlankRome, Washington, USA. ${ }^{9}$ DELTARES, Delft, The Netherlands. ${ }^{10}$ Department of Geosciences, University of Malta, Msida, Malta. ${ }^{11}$ MARE, Universidade Nova de Lisboa, Caparica, Portugal. ${ }^{12}$ University of the Aegean, Mytilene, Greece. ${ }^{13}$ University of Connecticut, Groton, USA. ${ }^{14}$ Universidade Federal Fluminense (UFF), Niterói, Brazil. ${ }^{15}$ University of Gothenburg, Gothenburg, Sweden. ${ }^{16}$ IFRE MER, LER/PAC, Toulon, France. ${ }^{17}$ Ministère de l'Environnement et des Forêts, Antananarivo, Madagascar. ${ }^{18}$ Toledo Technology Academy, Toledo, USA.

${ }^{19}$ Institute of Polar Sciences, Bologna, Italy. ${ }^{20}$ CIMA/ Universitade do Algarve, Faro, Portugal.

Received: 1 October 2020 Accepted: 23 December 2020 Published online: 19 January 2021

\section{References}

1. Amelineau F, Bonnet D, Heitz O, Mortreux V, Harding A, Karnovsky N, Walkusz W, Fort J, Grémillet D. Microplastic pollution in the Greenland Sea: background levels and selective contamination of planktivorous diving seabirds. Environ Pollut. 2016;219:1131-9 https://doi.org/10.1016/j.envpol.2016.09.017.

2. Barboza L, Vethaak A, Lavorante B, Lundebye A, Guilhermino L. Marine microplastic debris: an emerging issue for food security, food safety and human health. Mar Pollut Bull. 2018;133:336-48.

3. Barnes D, Galgani F, Thompson R, Barlaz M. Accumulation and fragmentation of plastic debris in global environments. Philos Trans R Soc B. 2009;364(1526):1985-98 https://doi.org/10.1098/rstb.2008.0205.

4. Beer S, Garm A, Huwer B, Dierking J, Gissel Nielsen T. No increase in marine microplastic concentration over the last three decades-a case study from the Baltic Sea. Sci Total Environ. 2018;621:1272-9 https://doi.org/10.1016/j. scitotenv.2017.10.101.

5. Borrelle S, Ringma J, Lavender Law K, Monnahan C, Lebreton L, McGivern A, Murphy E, Jambeck J, Leonard G, Hilleary M, Eriksen M, Possingham H, De Frond H, Gerber L, Polidoro B, Tahir A, Bernard M, Mallos N, Barnes M, Rochman C. Predicted growth in plastic waste exceeds efforts to mitigate plastic pollution. Science. 2020;369(6510):1515-8 https://doi.org/10.1126/science.aba3656.

6. Brandon J, Jones W, Ohman M. Multidecadal increase in plastic particles in coastal ocean sediments. Sci Adv. 2019;5(9) https://doi.org/10.1126/sciadv.aax0587.

7. Compa M, March D, Deudero S. Spatio-temporal monitoring of coastal floating marine debris in the Balearic Islands from sea-cleaning boats. Mar Pollut Bull. 2019;141:205-14 https://doi.org/10.1016/j.marpolbul.2019.02.027.

8. Courtene-Jones W, Quinn B, Ewin C, Gary S, Narayanaswamy B. Consistent microplastic ingestion by deep-sea invertebrates over the last four decades 
(1976-2015), a study from the north East Atlantic. Environ Pollut. 2019;244 503-12 https://doi.org/10.1016/j.envpol.2018.10.090.

9. Domènech F, Aznar F, Raga J, Tomas J. Two decades of monitoring in marine debris ingestion in loggerhead sea turtle, Caretta caretta, from the western Mediterranean. Environ Pollut. 2019;244:367-78 https://doi.org/10. 1016/j.envpol.2018.10.047.

10. Dunlop SW, Dunlop BJ, Brown M. Plastic pollution in paradise: daily accumulation rates of marine litter on Cousine Island, Seychelles. Mar Pollut Bull. 2020;151:110803 https://doi.org/10.1016/j.marpolbul.2019.110803.

11. Everaert G, Van Cauwenberghe L, De Rijcke M, Koelmans A, Mees J, Vandegehuchte $\mathrm{M}$, Janssen C. Risk assessment of microplastics in the ocean: Modelling approach and first conclusions. Environ Pollut. 2018;242:1930-8 https://doi.org/10.1016/j.envpol.2018.07.069.

12. García-Rivera S, Sanchez Lizazo J, Bellido Millan J. Spatial and temporal trends of marine litter in the Spanish Mediterranean seafloor. Mar Pollut Bull. 2018;137:252-61 https://doi.org/10.1016/j.marpolbul.2018.09.051.

13. Gerigny O, Brun M, Fabri MC, Tomasino C, Lemoigne M, Jadaud A, Galgani F. Seafloor litter from the continental shelf and canyons in French Mediterranean water: distribution, typologies and trends. Mar Pollut Bull. 2019;146:653-66 https://doi.org/10.1016/j.marpolbul.2019.07.030.

14. Geyer R, Jambeck J, Lavender Law K. Production, use, and fate of all plastics ever made. Sci Adv. 2017;3(7):e1700782 https://doi.org/10.1126/sciadv.1700782.

15. Green D, Kregting L, Boots B, Blockley D, Brickle P, Da Costa M, Crowley Q. A comparison of sampling methods for seawater microplastics and a first report of the microplastic litter in coastal waters of Ascension and Falkland Islands. Mar Pollut Bull. 2018;137:695-701 https://doi.org/10.1016/j. marpolbul.2018.11.004.

16. Hidalgo-Ruz V, Zimmer H, Gatta Rosemary M, Nunez P, Hinojosa I, Thiel M. Spatio-temporal variation of anthropogenic marine debris on Chilean beaches. Mar Pollut Bull. 2018;126:516-24 https://doi.org/10.1016/j. marpolbul.2017.11.014

17. Isobe A, Iwasaki S, Uchida K. Abundance of non-conservative microplastics in the upper ocean from 1957 to 2066. Nat Commun. 2019;417(2019):10 https://doi.org/10.1038/s41467-019-08316-9.

18. Jabeen K, Su L, Li J, Yang D, Tong C, Mu J, Shi H. Microplastics and mesoplastics in fish from coastal and fresh waters of China. Environ Pollut. 2017;221(2017):141-9 https://doi.org/10.1016/j.envpol.2016.11.055.

19. Jambeck J, Geyer R, Wilcox C, Siegler T, Perryman W, Andrady T, Narayan N, Lavender Law K. Plastic waste inputs from land intothe ocean. Science. 2015;347(622):768 https://doi.org/10.1126/science.1260352.

20. Kane A, Clare M, Miramontes E, Wogelius R, Tothwell J, Garreau P, Pohl F. Seafloor microplastic hotspots controlled by deep-sea circulation. Science. 2020;368(6495):1140-5 https://doi.org/10.1126/science.aba5899.

21. Kako S, Isobe A, Kataoka T, Hinata H. A decadal prediction of the quantity of plastic marine debris litteredon beaches of the east Asian marginal seas. Mar Pollut Bull. 2014;81 (1):174-84 https://doi.org/10.1016/.marpolbul.2014.01.057.

22. Kühn S, van Franeker JA, O'Donoghue A, Swiers A, Starkenburg M, van Werven B, Foekema E, Hermsen E, Egelkraut-Holtus M, Lindeboom H. Details of plastic ingestion and fibre contamination in North Sea fishes. Environ Pollut. 2020;257 https://doi.org/10.1016/j.envpol.2019.113569.

23. Lau W, Shiran Y, Bailey R, Cook E, et al. Evaluating scenarios toward zero plastic pollution. Science. 2020;368(6495):1140-5 https://doi.org/10.1126/ science.aba5899.

24. Lavender Law K, Moret-Ferguson S, Maximenko N, Proskurowski G, Peacock E. Plastic accumulation ' in the North Atlantic subtropical gyre. Science. 2010;329:1185-8 https://doi.org/10.1126/science.1192321.

25. Lavender Law K, Moret ferguson S, Goodwin D, Zettler E, DeForce E, Kulkula T, Prokurowski G. Distribution of surface plastic debris in the eastern Pacific Ocean from an 11-year data set. Environ Sci Technol. 2014;48(9):4732-8.

26. Lebreton L, Van de zwet J, Damsteg J, Slat B, Andrady A, reisser J. River plastic emissions to the world's oceans. Nat Commun. 2017;8:15611 https:// www.nature.com/articles/ncomms15611.

27. Lebreton L, Slat B, Ferrari F, Sainte Rose B, Aitken J, et al. Evidence that the Great Pacific Garbage Patch is rapidly accumulating plastic. Sci Rep. 2018; 8(1):4666 https://www.nature.com/articles/s41598-018-22939-w.

28. Liu K, Wu T, Wang X, Song Z, Wei N, Li D. Consistent transport of terrestria microplastics to the ocean through atmosphere. Environ Sci Technol. 2020; 53.18(2019):10612-9 https://doi.org/10.1021/acs.est.9b03427.

29. Lusher, et al. Incidence of marine debris in cetaceans stranded and bycaught in Ireland: recent findings and a review of historical knowledge. Environ Pollut. 2018;232:467-76.
30. Maes T, Barry J, Leslie H, Vethaak D, Nicolaus E, Law R, et al. Below the surface: Twenty-five years of seafloor litter monitoring in coastal seas of North West Europe (1992-2017). Sci Total Environ. 2018;630:790-8 https:// doi.org/10.1016/j.scitotenv.2018.02.245.

31. MEE/PRC (Ministry of Ecology and Environment, People Republic of China). Bulletin of marine ecological environmental status of China in 2018. 2019. http://hys.mee.gov.cn/dtxx/201905/P020190529532197736567.pdf.

32. Monahan P. Will plastic really outweigh fish in the ocean by 2050? Sci Mag News. 2016;2016:02 https://www.sciencemag.org/news/2016/02/will-plasticreally-outweigh-fish-ocean-2050\#.

33. Ostle C, Thompson R, Broughton D, Gregory L, Wootton M, Jones D. The rise in ocean plastics evidenced from a 60-year time series. Nat Commun. 2019;10(1):1622 https://www.nature.com/articles/s41467-019-09506-1.

34. Pabortsava K, Lampitt R. High concentrations of plastic hidden beneath the surface of the Atlantic Ocean. Nat Commun. 2020;4073(2020):11 https://doi. org/10.1038/s41467-020-17932-9.

35. Petry $M$, Benemann $V$. Ingestion of marine debris by the white-chinned petrel (Procellaria aequinoctialis): is it increasing over time off southern Brazil? Mar Pollut Bull. 2017;117(1-2):131-5 https://doi.org/10.1016/j. marpolbul.2017.01.073.

36. Pohl F, Eggenhuisen J, Kane C, Clare M. Transport and burial of microplastics in deep-arine sediments by turbidity currents. Environ Sci Technol. 2020;54(7):4180-9 https://doi.org/10.1021/acs.est.9b07527.

37. Ryan P, Dilley B, Ronconi R, Connan M. Rapid increase in Asian bottles in the South Atlantic Ocean indicates major debris inputs from ships. PNAS. 2019:116(42):20892-7 https://doi.org/10.1073/pnas.1909816116.

38. Schulz M, Neumann D, Fleet D, Matthies M. A multi-criteria evaluation system for marine litter pollution based on statistical analyses of OSPAR beach litter monitoring time series. Mar Environ Res. 2013;92:61-70 https:// doi.org/10.1016/j.marenvres.2013.08.013.

39. Strafella P, Fabi G, Despalatovic M, Cvitovic I, Fortibuoni T, et al. Assessment of seabed litter in the Northern and Central Adriatic Sea (Mediterranean) over six years. Mar Pollut Bull. 2019;141:24-35 https://doi.org/10.1016/j. marpolbul.2018.12.054.

40. Taylor M, Gwinnett C, Robinson L, Woodall L. Plastic microfibre ingestion by deep-sea organisms. Sci Rep. 2016;6:33997 https://www.nature.com/articles/ srep33997.

41. Tekman M, Krumpen T, Bergman M. Marine litter on deep Arctic seafloor continues to increase and spreads to the north at the HAUSGARTEN observatory. Deep-Sea Res I Oceanogr Res Pap. 2017;120:88-99 https://doi. org/10.1016/j.dsr.2016.12.011.

42. Thompson R, Olsen Y, Mitchell R, Davis A, Rowland S. Lost at sea: where is all the plastic? Science. 2004;304:838 https://doi.org/10.1126/science. 1094559.

43. Van Franeker J, Lavender Law K. Seabirds, gyres and global trends in plastic pollution. Environ Pollut. 2015;203:89-96 https://doi.org/10.1016/j.envpol. 2015.02.034

44. Walther B, Kunz A, ShenHu C. Type and quantity of coastal debris pollution in Taiwan. Mar Pollut Bull. 2018;135:862-72 https://doi.org/10.1016/j. marpolbul.2018.08.025

45. Wilcox C, Hardesty BD, Lavender law K. Abundance of floating plastic particles is increasing in the Western North Atlantic Ocean. Environ Sci Technol. 2019;54(2):790-6 https://doi.org/10.1021/acs.est.9b04812.

46. Willis K, Erikwen R, Wilcox C, Hardesty BD. Microplastic distribution at different sediment depths in an urban estuary. Front Mar Sci. 2017; 19 December 2017. https://doi.org/10.3389/fmars.2017.00419.

47. Woodall L, Sanchez Vidal A, Canals M, Paterson G, et al. The deep sea is a major sink for microplastic debris. R Soc Open Sci. 2014;1(4):140317 https:// doi.org/10.1098/rsos.140317.

48. Zablotski Y, Kraak S. Marine litter on the Baltic seafloor collected by the international fish-trawl survey. Mar Pollut Bull. 2019;141:448-61 https://doi. org/10.1016/j.marpolbul.2019.02.014.

49. Zhou C, Liu X, Wang Z, Yang T, et al. Assessment of marine debris in beaches or seawaters around the China Seas and coastal provinces. Waste Manag. 2016;48:652-60 https://doi.org/10.1016/j.wasman.2015.11.010.

\section{Publisher's Note}

Springer Nature remains neutral with regard to jurisdictional claims in published maps and institutional affiliations. 